\title{
$\mathrm{CuO}$ 가 코팅된 $\mathrm{Cu}$ 분말을 혼합한 Camphene 슬러리의 동결건조에 의한 $\mathrm{Cu}$ 다공체 제조
}

\author{
방수룡 · 오승탁* \\ 서울과학기술대학교 신소재공학과
}

\section{Fabrication of Porous Cu by Freeze-drying Process of Camphene Slurry with CuO-coated Cu Powders}

\author{
Su-Ryong Bang and Sung-Tag Oh* \\ Department of Materials Science and Engineering, Seoul National University of Science \\ and Technology, Seoul 139-743, Korea
}

(Received June 2, 2014; Revised June 9, 2014; Accepted June 10, 2014)

\begin{abstract}
This study reports a simple way of fabricating the porous $\mathrm{Cu}$ with unidirectional pore channels by freeze drying camphene slurry with $\mathrm{Cu}$ oxide coated $\mathrm{Cu}$ powders. The coated powders were prepared by calcination of ballmilled powder mixture of $\mathrm{Cu}$ and $\mathrm{Cu}$-nitrate. Improved dispersion stability of camphene slurry could be achieved using the $\mathrm{Cu}$ oxide coated $\mathrm{Cu}$ powders instead of pure $\mathrm{Cu}$ powders. Pores in the frozen specimen at $-25^{\circ} \mathrm{C}$ were generated by sublimation of the camphene during drying in air, and the green bodies were sintered at $750^{\circ} \mathrm{C}$ for $1 \mathrm{~h} \mathrm{in} \mathrm{H}_{2}$ atmosphere. XRD analysis revealed that the coated layer of $\mathrm{Cu}$ oxide was completely converted to $\mathrm{Cu}$ phase without any reaction phases by hydrogen heat treatment. The porous $\mathrm{Cu}$ specimen prepared from pure $\mathrm{Cu}$ powders showed partly large pores with unidirectional pore channels, but most of pores were randomly distributed. In contrast, large and aligned parallel pores to the camphene growth direction were clearly observed in the sample using $\mathrm{Cu}$ oxide coated $\mathrm{Cu}$ powders. Pore formation behavior depending on the initial powders was discussed based on the degree of powder rearrangement and dispersion stability in slurry.
\end{abstract}

Keywords: Porous $\mathrm{Cu}, \mathrm{Cu}$ oxide coated $\mathrm{Cu}$ powder, Dispersion stability, Freeze-drying

\section{1. 서 론}

구조용 재료에서는 내부에 존재하는 기공이 강도저하의 요인으로 작용하기 때문에 제거되어야 할 대상이다. 그러 나 기공은 재료의 무게감소, 비표면적 증가 및 통기성을 가능하게 하는 장점이 있어 기공을 가지는 다공체는 구조 재료의 경량화, 촉매용 담체 및 오염물질 제거용 필터 등 으로 산업적인 응용이 가능한 측면이 있다[1-3].

다공체를 제조하는 대표적인 방법으로는 부분소결[4], 기공 형성제 혼합과 제거[5], replica template[6] 및 발포공 정[7]으로 구분할 수 있다. 기공 형성제를 이용한 다공체 제조 공정 중에서는 동결건조법이 많은 주목을 받고 있다.
고체분말과 동결제를 혼합한 슬러리를 일방향으로 응고시 킨 후 동결제의 승화처리로 기공을 형성시키는 동결건조 법은 동결제의 응고가 한쪽 방향으로만 일어나기 때문에 최종적으로 형성된 기공은 방향성을 갖게 되며, 또한 재료 내부의 기공이 외부와 연결된 개기공 형태의 거대기공이 존재하고 기공의 양과 크기를 동결제 첨가량 및 동결조건 으로 쉽게 조절할 수 있는 장점이 있다[8-9].

동결건조법은 $\mathrm{Al}_{2} \mathrm{O}_{3}$ 및 $\mathrm{SiC}$ 등 다양한 다공성 세라믹 제조에 적용되고 있으나, 금속분말이 혼합된 슬러리의 경 우에는 분산안정성의 제어에 어려움이 있기 때문에 금속 계 다공체의 제조에는 한계가 있었다. 이러한 문제점을 해 결하고자 본 연구그룹에서는 금속분말대신 금속산화물 분

*Corresponding Author : Sung-Tag Oh, TEL: +82-2-970-6631, FAX: +82-2-973-6657, E-mail: stoh@seoultech.ac.kr 
말을 이용하여 분산안정성을 갖는 슬러리를 제조하고, 동 결건조 후 수소환원처리를 거쳐 금속상으로 제조하는 공 정을 적용한 바 있다. 이러한 공정으로 제조한 $\mathrm{Cu}, \mathrm{W}, \mathrm{Mo}$ 등의 금속 다공체는 방향성을 갖는 거대기공의 형성과 공 정조건에 따른 기공의 양 및 크기 변화 등 기공특성의 제 어가 가능함을 확인할 수 있었다[10-12]. 그러나 금속산화 물 분말의 수소환원을 이용하는 공정은 환원에 따른 성형 체의 커다란 부피변화와 함께 완전한 환원상 형성을 위한 장시간 열처리 등의 문제점이 있어, 이의 해결을 위한 새 로운 공정의 도입이 요구되고 있다.

따라서 본 연구에서는 금속분말에 금속산화물을 코팅하 는 방법을 도입하여 분산안정성을 갖는 슬러리로 제조하 고 이를 동결건조한 후, 단시간의 수소환원 처리를 통하여 금속 계 다공체를 제조하고자 하였다. 동결제로는 camphene 을 선택하였고 $\mathrm{Cu}$ 분말에 화학적 방법으로 $\mathrm{Cu}$ 산화물을 코 팅하여 미세조직 및 슬러리 내에서의 분산안정성을 조사 하였다. 또한 동결건조 및 수소분위기에서의 소결을 통하 여 방향성 기공을 갖는 금속 다공체를 제조하고 특성을 평가하고자 하였다.

\section{2. 실험방법}

본 연구에서는 순도 $99.9 \%$, 평균 입자크기 $10 \mu \mathrm{m}$ 의 $\mathrm{Cu}$ 분말(Alfa Aesar, USA)을 원료로 사용하였으며, 그림 1에 분말의 형상을 나타내었다. 분말 표면에 $\mathrm{Cu}$ 산화물의 코 팅을 위해서 Cu-nitrate $\left(\mathrm{Cu}\left(\mathrm{NO}_{3}\right)_{2} \cdot 3 \mathrm{H}_{2} \mathrm{O}\right.$, Kojundo Chem. Lab., Japan)를 원료로 사용하였으며, $\mathrm{Cu}$ 분말에 대하여 하 소한 후 $\mathrm{CuO}$ 가 $38 \mathrm{vol} \%$ 가 되도록 칭량하여 에탄올 용액 에 충분히 용해하였다. 균일한 혼합을 위하여 $\mathrm{Cu}$-nitrate 용액에 $\mathrm{Cu}$ 분말과 $\mathrm{Al}_{2} \mathrm{O}_{3}$ 볼을 첨가하여 10 시간동안 밀링 한 후, $250^{\circ} \mathrm{C}$ 의 대기 중에서 2 시간동안 하소하였다. 동결 제로는 camphene $\left(\mathrm{C}_{10} \mathrm{H}_{16}, 95 \%\right.$, Sigma-Aldrich Co., USA) 을 사용하였으며, 하소한 분말과 동결제 무게대비 $0.1 \%$ 의 분산제 (oligomeric polyester)를 동결제와 함께 혼합한 후 약 $50^{\circ} \mathrm{C}$ 에서 magnetic stirrer를 이용하여 30 분동안 혼합하 였다. 제조된 슬러리에서 $\mathrm{Cu}$-nitrate가 코팅된 $\mathrm{Cu}$ 분말의 양은 $10 \mathrm{vol} \%$ 이 되도록 하였다.

슬러리의 동결은 직경 $10 \mathrm{~mm}$ 의 실린더 형태를 갖는 자 체 제작한 금형을 이용하였으며, 하부만 $-25^{\circ} \mathrm{C}$ 로 냉각된 에 탄올 bath에 위치하도록 하여 동결 중의 응고열이 아래쪽 으로만 전달되게 하였다[12]. 금형에서 분리한 동결시편은 대기 중에서 48 시간동안 유지하는 승화처리를 통하여 camphene 동결제를 제거하였다. 성형체는 $300^{\circ} \mathrm{C}$ 까지 가열 한 후 1 시간동안 수소환원 처리하였고 계속해서 승온속도 약 $4^{\circ} \mathrm{C} / \mathrm{min}$ 로 $750^{\circ} \mathrm{C}$ 까지 가열하여 1 시간동안 소결하였다.
슬러리의 분산안정성에 미치는 분말특성의 영향을 평가 하고자 분산안정화도 분석기 (Turbiscan, France)를 이용하 여 $70^{\circ} \mathrm{C}$ 에서 backscattering percent를 시간의 함수로 측정 하였다. 하소한 분말과 수소환원한 성형체의 상변화는 $\mathrm{XRD}$ 를 이용하여 분석하였고, 분말의 미세조직과 소결체 에서의 기공특성은 SEM으로 분석하였다.

\section{3. 실험결과 및 고찰}

그림 2는 $\mathrm{Cu}$-nitrate의 혼합과 하소공정을 이용하여 $\mathrm{Cu}$ 분말 표면에 $\mathrm{Cu}$ 산화물을 코팅한 분말의 미세구조를 관찰 한 사진이다. 그림 1 의 순수한 $\mathrm{Cu}$ 분말과 비교할 때, 표면 부위에는 판상형태의 새로운 입자가 코팅층을 형성하며 존재함을 알 수 있으며, 형성된 상의 해석을 위하여 XRD 분석을 행하였다. 그림 $3(\mathrm{a})$ 는 $\mathrm{Cu}$-nitrate와 혼합한 $\mathrm{Cu}$ 분말 을 $250^{\circ} \mathrm{C}$ 에서 하소한 시편에 대한 $\mathrm{XRD}$ 결과로서, 순수한 $\mathrm{Cu}$ 상이외에 $\mathrm{CuO}$ 와 $\mathrm{Cu}_{2} \mathrm{O}$ 상이 존재함을 알 수 있다. 따라 서 이러한 결과를 그림 2의 미세구조사진과 비교할 때,

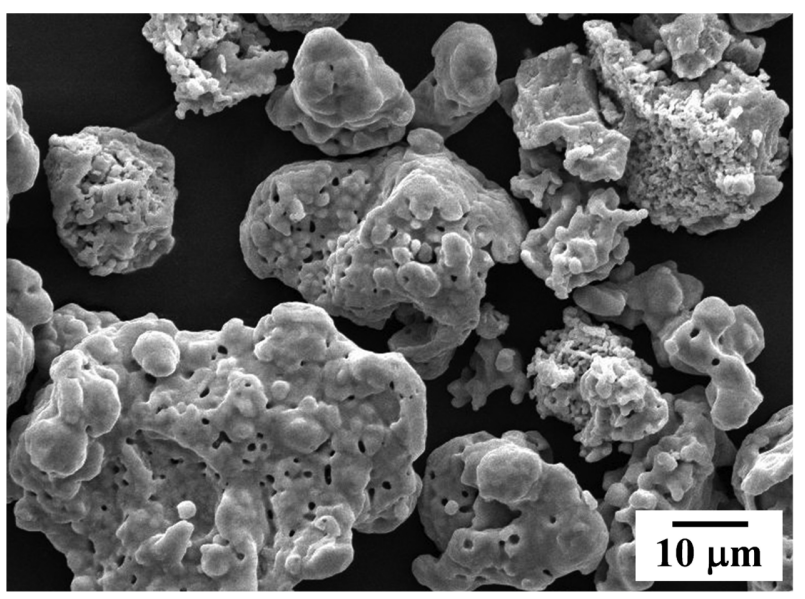

Fig. 1. SEM image of $\mathrm{Cu}$ powder.

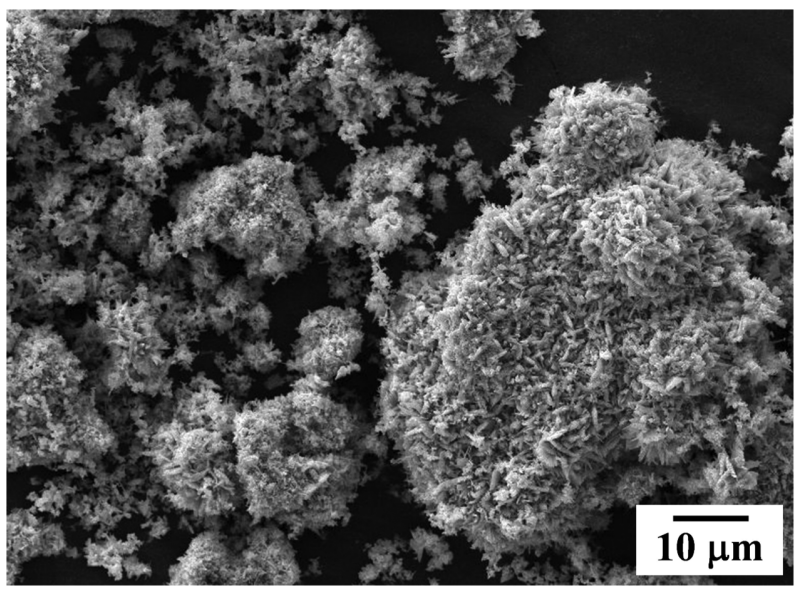

Fig. 2. SEM image of ball-milled and calcined $\mathrm{Cu} / \mathrm{Cu}$-nitrate mixture. 


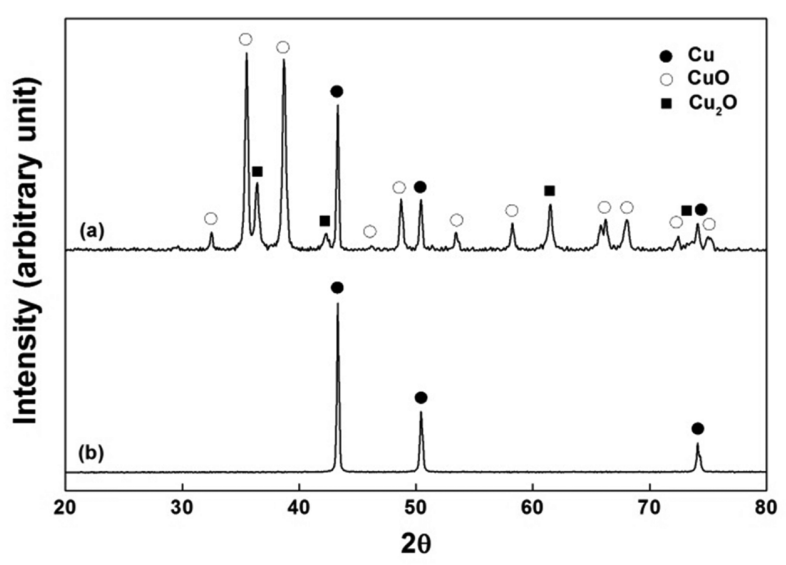

Fig. 3. XRD profiles of the powders at different stages of processing; (a) after calcination in air at $250^{\circ} \mathrm{C}$ for $2 \mathrm{~h}$ and (b) after sintering in hydrogen atmosphere at $750^{\circ} \mathrm{C}$ for $1 \mathrm{~h}$.

$\mathrm{Cu}$ 표면부위에 형성된 새로운 입자는 $\mathrm{Cu}$ 산화물이며 전체 적으로 균일한 코팅층을 형성하고 있음을 나타낸다.

순수한 $\mathrm{Cu}$ 또는 $\mathrm{Cu}$ 산화물이 코팅된 $\mathrm{Cu}$ 분말이 혼합된 camphene 슬러리에서의 분산안정성변화를 측정하여 그림 4 에 나타내었다. 분산안정성을 나타내는 측정 값인 backscattering percent는 슬러리가 담겨진 용기에 빔을 가 했을 때 위치에 따라 반사되어 나오는 빔의 양을 시간의 함수로 나타낸 것으로, 분산안정성을 갖는 경우는 시간에 따라 입자의 침강이나 응집이 없기 때문에 backscattering percent는 일정한 값을 나타내게 된다[13]. 그림 4(a)와 같 이 순수한 $\mathrm{Cu}$ 분말이 혼합된 슬러리의 경우는 시간이 경과 함에 따라 넓은 범위의 backscattering percent의 변화를 나 타내나, $\mathrm{Cu}$ 산화물이 코팅된 $\mathrm{Cu}$ 분말이 혼합된 경우 (그림 $4 \mathrm{~b})$ 는 변화폭이 상대적으로 적게 나타낸다. 따라서 본 실 험에서 적용한 $\mathrm{Cu}$ 산화물의 코팅 공정은 camphene슬러리 의 분산안정성을 증가시킬 수 있음을 보여준다.

그림 5(a)와 (b)는 각각 순수한 $\mathrm{Cu}$ 및 $\mathrm{Cu}$ 산화물이 코팅

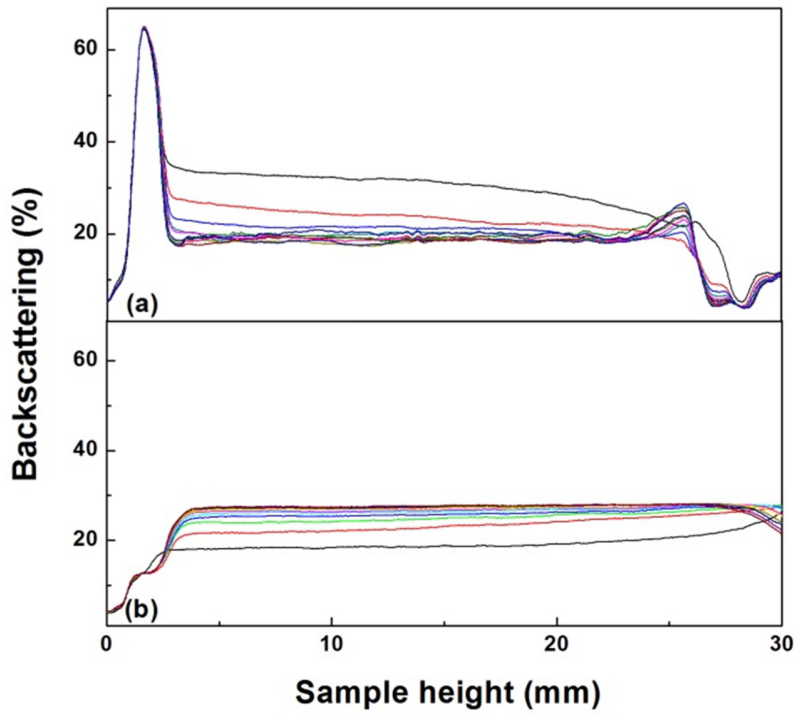

Fig. 4. Backscattering intensity versus the height in the sample at different times for the camphene slurries mixed with (a) pure $\mathrm{Cu}$ powder and (b) $\mathrm{Cu}$ oxide coated $\mathrm{Cu}$ powder.

된 $\mathrm{Cu}$ 분말의 슬러리를 동결건조한 후 $750^{\circ} \mathrm{C}$ 의 수소분위 기에서 1 시간동안 소결한 시편의 미세구조 사진이다. 그림 5(a)에서 보여주듯이, 순수한 $\mathrm{Cu}$ 분말을 사용하여 동 결건조한 경우는 방향성을 가지는 거대기공이 일부 관찰 되나 대부분이 무질서한 형태를 나타내고 있다. 반면 $\mathrm{Cu}$ 산화물이 코팅된 $\mathrm{Cu}$ 분말의 경우는 그림 3(b)의 $\mathrm{XRD}$ 결과 와 같이 수소분위기의 소결을 통하여 모두 $\mathrm{Cu}$ 상으로만 환 원되며, 순수한 $\mathrm{Cu}$ 분말을 사용한 경우와 비교하여 상대적 으로 뚜렷한 방향성 기공의 형성과 규칙적인 분포를 관찰 할 수 있다.

일반적으로 동결건조법으로 제조한 시편에서 관찰되는 방향성 거대기공은 슬러리의 동결 시 camphene 동결제가 일방향으로 응고되고 계속해서 건조과정을 거쳐 동결제 결정이 승화되어 제거되기 때문에 형성된다[8]. 본 연구의
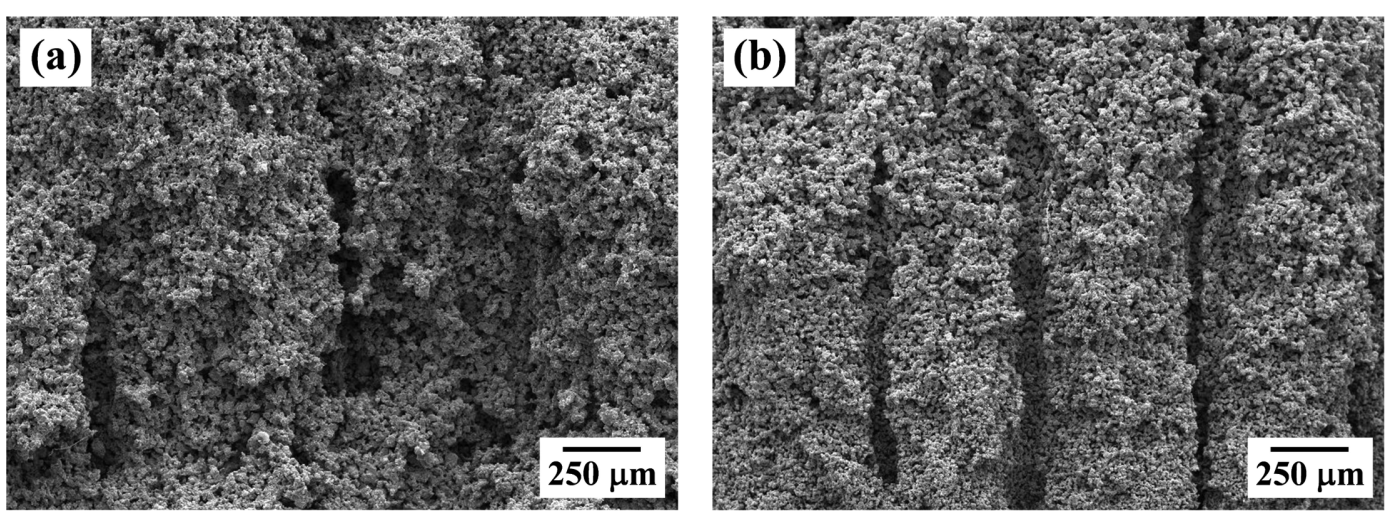

Fig. 5. SEM micrographs of the porous $\mathrm{Cu}$, sintered in hydrogen atmosphere at $750^{\circ} \mathrm{C}$ for $1 \mathrm{~h}$ using a (a) $\mathrm{Cu}$ powder and (b) $\mathrm{Cu}$ oxide coated $\mathrm{Cu}$ powder. 

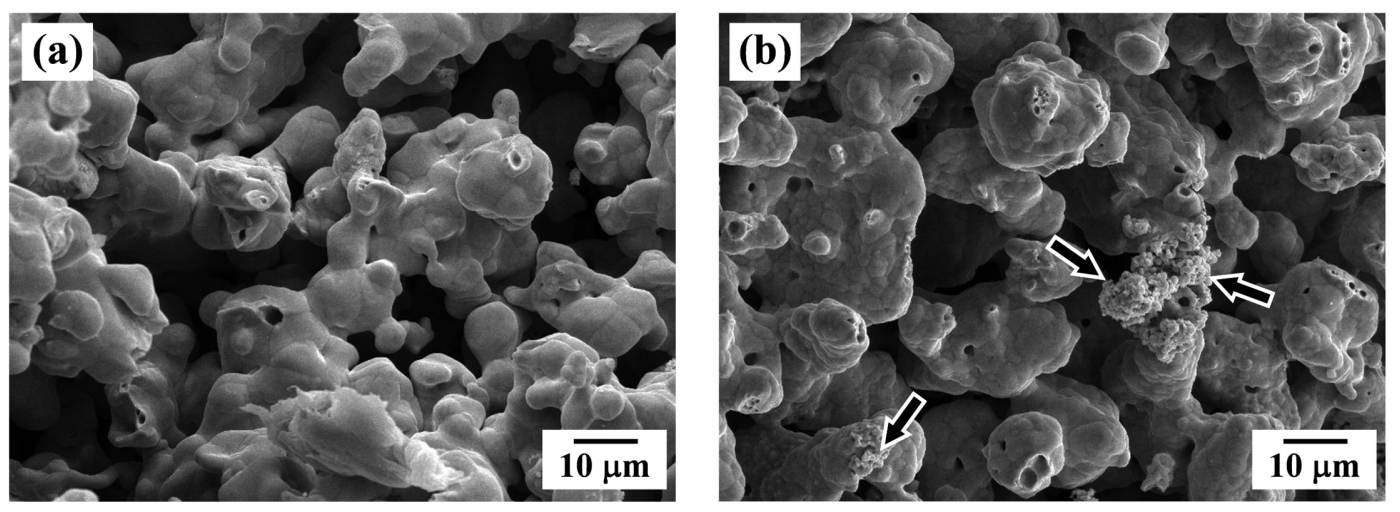

Fig. 6. SEM micrographs for the strut of porous $\mathrm{Cu}$, prepared from (a) $\mathrm{Cu}$ powder and (b) $\mathrm{Cu}$ oxide coated $\mathrm{Cu}$ powder.

경우는 그림 5에서 나타낸 시편의 아래쪽으로만 응고열이 전달되기 때문에 camphene은 아래쪽부터 위쪽으로 성장 하여 방향성 기공을 보여준다. 한편 고체입자가 포함된 슬 러리의 동결거동은 동결제 결정의 성장과정 중 고체입자 의 재배열과 슬러리 내 분산안정성에 의존한다[14-16]. 그림 4(a)에서 설명한 바와 같이, 순수한 $\mathrm{Cu}$ 분말을 혼합한 camphene슬러리의 낮은 분산안정성으로 응고과정 중 고 체입자의 빠른 재배열이 어려워지기 때문에 방향성을 가 지는 거대기공으로의 성장에 제약을 받는다. 따라서 순수 한 $\mathrm{Cu}$ 분말을 사용하는 경우보다는 본 연구에서 적용한 $\mathrm{Cu}$ 산화물이 코팅된 $\mathrm{Cu}$ 분말을 사용하는 공정이 방향성 기 공을 가지는 다공체 제조에 더 적합함을 확인할 수 있다.

그림 6(a)와 (b)는 각각 순수한 $\mathrm{Cu}$ 및 $\mathrm{Cu}$ 산화물이 코팅 된 $\mathrm{Cu}$ 분말을 사용하여 소결한 다공체에서 미세기공 주변 의 지지대 (strut)를 나타내는 미세조직 사진이다. 동일한 분말크기와 소결조건을 적용했음에도 불구하고 $\mathrm{Cu}$ 산화물 이 코팅된 $\mathrm{Cu}$ 분말을 사용한 경우에서 더 많은 입자 및 목 성장이 이루어져 있음을 알 수 있으며, 화살표로 표시한 것 과 같이 일부 나노크기의 $\mathrm{Cu}$ 입자가 관찰된다. 기존연구에서 보고된 바와 같이[17], 이러한 향상된 입자 및 목성장은 나 노-마이크로 크기의 분말이 혼합된 성형체에서 나노크기 입 자에 의한 소결성 향상에 기인한 것으로 해석된다.

\section{4. 결 론}

동결건조법을 이용한 금속 계 다공체 제조에서 금속분 말 대신 금속산화물 입자가 코팅된 금속분말을 사용하여 슬러리의 분산안정성을 제어하고 후속 환원 열처리를 거 치는 새로운 공정을 도입하였다. Cu-nitrate의 용해와 하소 를 통하여 $\mathrm{Cu}$ 분말 표면에 $\mathrm{Cu}$ 산화물이 코팅된 복합분말을 합성한 후 동결제 camphene과 혼합하여 슬러리로 제조하 였다. 순수한 $\mathrm{Cu}$ 분말로만 혼합한 슬러리와 비교할 때 $\mathrm{Cu}$ 산화물이 코팅된 $\mathrm{Cu}$ 분말의 경우는 우수한 분산안정성을
나타내었으며, 슬러리를 동결 건조한 후 $750^{\circ} \mathrm{C}$ 의 수소분 위기에서 소결한 시편들은 모두 순수한 $\mathrm{Cu}$ 상으로만 존재 함을 확인하였다. 순수한 $\mathrm{Cu}$ 분말을 사용하여 제조한 다공 체에서는 방향성을 가지는 거대기공이 일부 관찰되나 대 부분이 무질서한 형태를 나타내었다. 그러나 $\mathrm{Cu}$ 산화물이 코팅된 $\mathrm{Cu}$ 분말의 경우는 상대적으로 뚜렷한 방향성 기공 의 형성과 규칙적인 분포를 나타내어, 본 연구에서 적용한 공정으로 요구되는 기공구조를 갖는 다공체의 제조가 가 능함을 확인하였다. 원료분말 특성에 따른 이러한 기공구 조의 변화는 camphene결정의 성장과정 중 고체입자의 재 배열과 관련된 슬러리 내 분산안정성의 영향으로 설명하 였다.

\section{감사의 글}

이 연구는 서울과학기술대학교 교내연구비의 지원으로 수행되었습니다.

\section{참고문헌}

[1] J. Banhart: Prog. Mater. Sci., 46 (2001) 559.

[2] M.-J. Suk and Y.S. Kwon: J. Kor. Powd. Met. Inst., 8 (2001) 215 (Korean).

[3] T. Ohji and M. Fukushima: Intern. Mater. Rev., 57 (2012) 115.

[4] S.-T. Oh, K. Tajima, M. Ando and T. Ohji: J. Am. Ceram. Soc., 83 (2000) 1314.

[5] N.-H. Kim, H. Song, S.-C. Choi and Y.-H. Choa: J. Kor. Powd. Met. Inst., 16 (2009) 262 (Korean).

[6] G. Walther, B. Klöden, T. Büttner, T. Weissgärber, B. Kieback, A. Böhm, D. Naumann, S. Saberi and L. Timberg: Adv. Eng. Mater., 10 (2008) 803.

[7] D.-H. Yang, B.-Y. Hur and S.-R. Yang: J. Alloys Comp., 461 (208) 221.

[8] T. Fukasawa, M. Ando, T. Ohji and S. Kanzaki: J. Am. Ceram. Soc., 84 (2001) 230. 
[9] B.-H. Yoon, E.-J. Lee, H.-E. Kim and Y.-H. Koh: J. Am. Ceram. Soc., 90 (2007) 1753.

[10] S.-T. Oh, S.-Y. Chang and M.-J. Suk: Trans. Nonferrous Met. Soc. China, 22 (2012) s688.

[11] N.-Y. Kwon and S.-T. Oh: J. Kor. Powd. Met. Inst., 19 (2012) 259 (Korean).

[12] W. Lee and S.-T. Oh: J. Kor. Powd. Met. Inst., 19 (2012) 446 (Korean).

[13] O. Mengual, G. Meunier, I. Cayré, K. Puech and P. Snabre:
Talanta, 50 (1999) 445.

[14] D.R. Uhlmann, B. Chalmers and K.A. Jackson: J. Appl. Phys., 35 (1964) 2986.

[15] S. Deville, E. Maire, G. Bernard-Granger, A. Lasalle, A. Bogner, C. Gauthier, J. Leloup and C. Guizard: Nature Mater., 8 (2009) 966.

[16] S. Deville: Adv. Eng. Mater., 10 (2008) 155.

[17] W.-K. You, J.-P. Choi, S.-M. Yoon and J.-S. Lee: Powder Techn., 228 (2012) 199. 